for continuing professional development (CPD).

(e) Academic links with university departments should exist and be identified. The links need not be confined to departments of psychiatry. University departments should be asked to furnish for the job description an account of the academic ties.

(f) Other links should also be described, e.g. with social services, health promotion services and voluntary agencies.

(g) Membership on committees and planning groups should be identified.

(h) On call duties require specification.

7. Facilities:

(a) The nature (in-patient, out-patient, daypatient) of the facilities should be described.

An average of three beds per 100000 population should be reserved for the management of substance misuse, with adjustments up or down according to socio-demographic factors and other facilities which might be available. In rural settings, where community support may be thinly spread, relatively greater numbers may require in-patient management. There should be provision for special need categories of patient, such as those with alcoholic brain damage and drug misusers who are HIV-symptomatic.

(b) Their sites should also be outlined.

(c) The number of junior doctors and paramedical staff will be precisely stated. Because of the role the consultant will undertake in training psychiatrists, there is a need for rotation of psychiatric trainees to the consultant. Junior staff may also usefully include trainee general practitioners.
Because of the many social problems of patients, social work input should have been agreed. Treatment conducted or supervised by psychologists is undertaken in many areas, is undergoing rapid development, but is time consuming; for its purpose the service will require specified sessions of a psychologist. At least one community psychiatric nurse is necessary. The number of other nurses depends on the present and anticipated build up of out-patient. day-patient and in-patient services. Access to occupational therapy is required for both day-patients and in-patients. The provision of a proper level of nursing and other staff should not await the development of services but is necessary for the growth of facilities.

A full-time secretary is crucial for the medical staff. The social work nursing and psychology services require additional secretarial assistance.

(d) Office and other facilities that are avallable require specification, keeping in mind the number of disciplines involved in alcohol and drug dependence. Space for teaching is required. Accommodation should be available for meetings by self-help organisations such as Alcoholics Anonymous.

8. Within a health district the responsibility for relevant patients should be delimited between general psychiatrists and the speciality consultant. In the case of an appointment to a regional or subregional unit, the psychiatrists within the districts covered by the unit would continue to undertake the clinical care of many patients with alcohol or drug problems, in view of the number of persons so affected.

\title{
Queen's Birthday Honours List
}

The following awards were recetved by members of the College in the Queen's Birthday Honours List:

Dr Rosemary Wool CB

Professor Tom Arie CBE

Professor Robert Bluglass CBE

Dr Judy Greenwood OBE

Professor George Brown OBE 